\title{
A Study on Prevalence of Hearing Loss as a Complication of Diabetes
}

\author{
A. Dayanand, J. Dheebika, S. Prathula and S. Palaninathan
}

\begin{abstract}
The aim of this study is to assess the hearing loss prevalence in association with diabetes \& correlate it with age and duration of diabetes. This study was done in outpatient and inpatient department of ENT \& endocrinology department in PSG Institute of Medical Science and Research, Coimbatore, Tamilnadu, from July 2012 -2014. Evaluation of 200 patients with otoscopic examination of canal and tympanic membrane status, worked up with PTA .Audiogram was analyzed for hearing loss \&classified by WHO criteria found that $72 \%$ individuals with diabetes were noted to have mild SNHL ,20 \% with moderate SNHL,3\% moderate severe SNHL, $4 \%$ severe ,1\% with profound hearing loss .In our study we concluded that after analyzing audiogram of diabetic patient ,they are more prone to develop mild to moderate SNHL and duration of diabetes and gender were found to have no effect on incidence of hearing loss.
\end{abstract} loss.

Index Terms - Diabetes, audiogram, sensorineural hearing

\section{INTRODUCTION}

Hearing impairment is the most frequent sensory deficit in human populations, affecting more than 250 million people in the world. Diabetes Mellitus is a metabolic disorder, due to relative or absolute lack of insulin resulting in elevated blood glucose levels associated with long term vascular and neurological complications. Among glucose metabolism disorders, diabetes mellitus is the one most commonly related with auditory disorders. The complex arrangement of inner ear makes it potential target of hyperglycemic damage. Diabetic patients are more prone to complications of hyperglycemic, as all body cells are exposed to high levels of plasma glucose. The organ of corti cells are important structures for hearing mechanism and turn out to be the potential target for damage, due to high glycemic levels, micro vascular compromise, their complex structure and arrangement. Thus, screening of these patients at a high risk of developing sensory neural hearing loss, will aid in early diagnosis and management.

\section{AIM OF THE STUDY}

- To Study the prevalence of Hearing loss its association with Diabetes.

- To assess the hearing loss in diabetics and correlate it with age and duration of diabetes.

Published on August 29, 2020.

A. Dayanand, PSG Institute of Medical Sciences \& Research, India.

J. Dheebika, PSG Institute of Medical Sciences \& Research, India.

(corresponding e-mail: deepidee88@ gmail.com)

S. Prathula, PSG Institute of Medical Sciences \& Research, India.

S. Palaninathan, PSG Institute of Medical Sciences \& Research, India.

\section{MATERIALS}

This is a cross-sectional study in which evaluation of study population who were diagnosed with diabetes mellitus study method undergoing treatment on Out-Patient or InPatient basis in department of ENT and Endocrinology. In PSG Institute of Medical Science \& Research. Coimbatore, Tamilnadu from July 2012 to July 2014 were considered.

- History of every patient was taken in detail and importance was given on their presenting complaints. Any significant past history of ear discharge. Hearing loss or previous ear surgeries were elicited. History of duration of diabetes and mode of treatment were given importance.

- All the patients were taken up for Otoscopic examination, in which the ear canal and status of tympanic membrane were assessed.

\section{Inclusion Criteria for cases considered in the study \\ - Known cases of Diabetes mellitus \\ - Age-group > 30 years to $<60$ years \\ - Both genders}

\section{Exclusion Criteria for cases}

- Individuals involved in occupations exposing to loud noise.

- Individuals with previous history of ear discharge/hearing loss/ tinnitus/ear surgery

- Otoscopic examination showing any ear pathology like wax, discharge, retracted tympanic membrane, perforated tympanic membrane or tympanosclerosis.

- Patients unwilling to comply with the study.

\section{METHODOLOGY}

All 200 patients were worked up with a pure tone audiometry. The audiogram was analyzed for hearing loss and if present it will be classified according to WHO classification. Pure Tone Audiometry is a routine audiometric evaluation and the resulting pure tone audiogram is used as a basic description of the degree of hearing loss. Audiological examination was performed using a Pure Tone Audiometer model GS1 61, in a soundproof room in the ENT department, PSG Institute of Medical Sciences \& research. Earphones were used to test hearing by air conduction and a small vibrator, which was placed over the mastoid was used to test hearing by bone conduction. All audiometers are incorporated with a calibration circuit, which allows the output sound level to be set at particular frequency. The signals presented to the subject by the audiometer were all characterized by its sound pressure level, frequency and wave form which were all delivered at 
controlled rates.

The entire procedure and purpose of the test was explained in detail to the patients. Biological calibration of the system was done on daily basis before starting the procedure. Both air and bone conduction were tested for each ear.

\section{RESUlT}

In this study, analysis of 200 patients diagnosed mellitus was done in the Department of E.N.T, PSG Institute of Medical Sciences\& Research from July 2012 to July 2014 to determine the incidence of hearing loss as a complication of diabetes mellitus. Detailed evaluation of each case was done comprising of the history, clinical examination including otoscopic examination with otoscopic and pure tone audiometry. The clinical data was collected by means of a proforma and the observations from the audiogram were analyzed with the Master chart as shown in the Annexure. In our study of 200 diabetic patients, 110 (55\%) cases out to have sensorineural hearing loss.

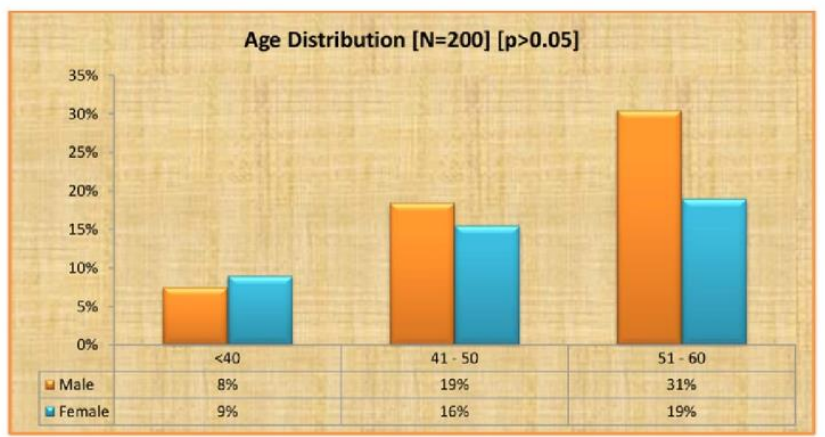

Fig.1. Age distribution of hearing loss.

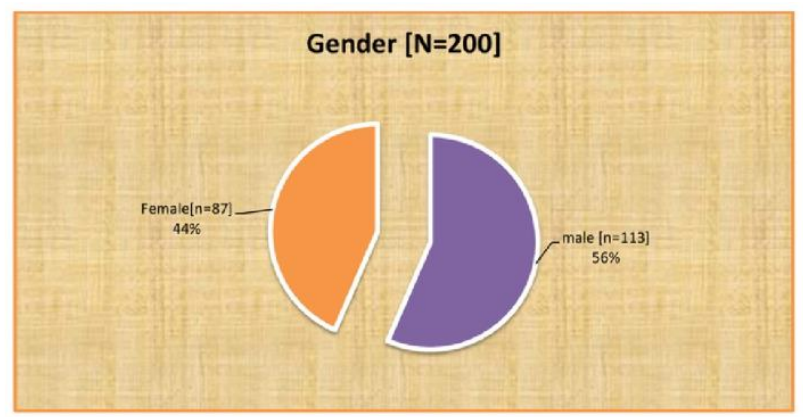

Fig. 2. Gender distribution.

TABLE I: OVERALL DISTRIBUTION OF HEARING LOSS

\begin{tabular}{lcc}
\hline Hearing Loss & $\mathrm{n}$ & $(\%)$ \\
\hline Bilateral - Normal hearing & 90 & 45 \\
Bilateral -hearing loss & 95 & 47 \\
Unilateral hearing loss & & \\
Left & 11 & 6 \\
Right & 4 & 2 \\
Total & 200 & 100 \\
\hline
\end{tabular}

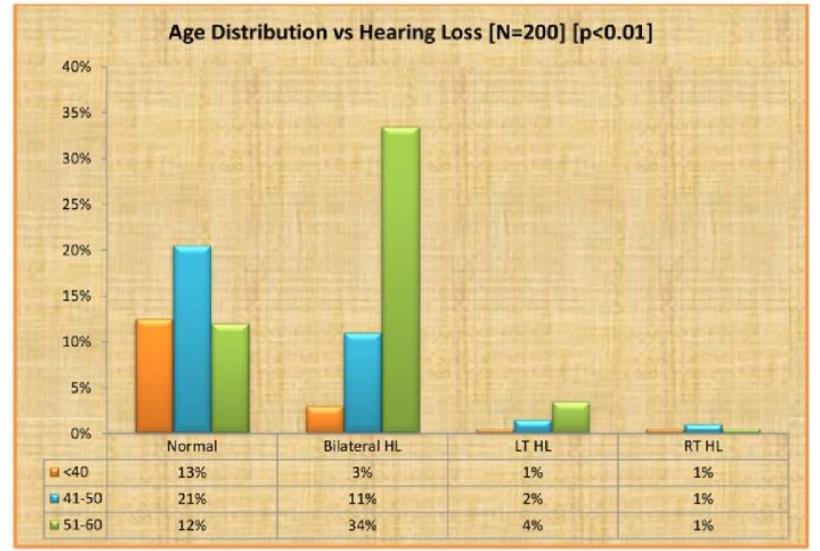

Fig. 3. Hearing loss in various Age groups.

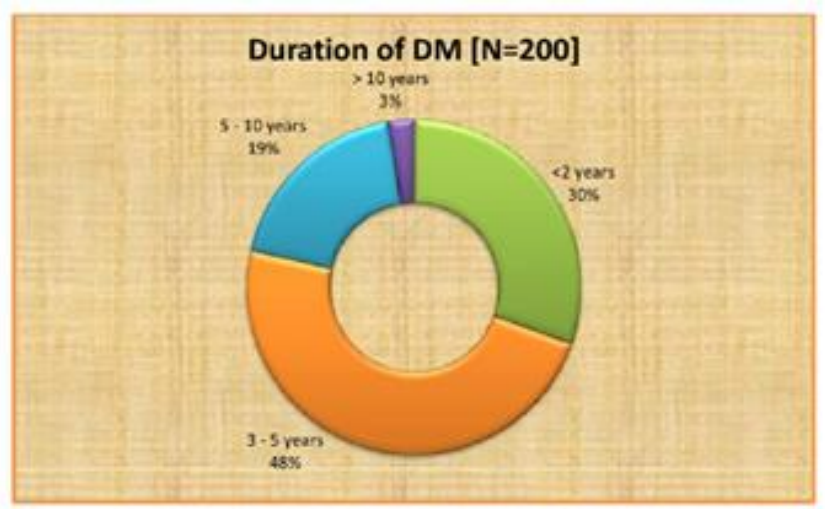

Fig. 4. Duration of DM in study population.

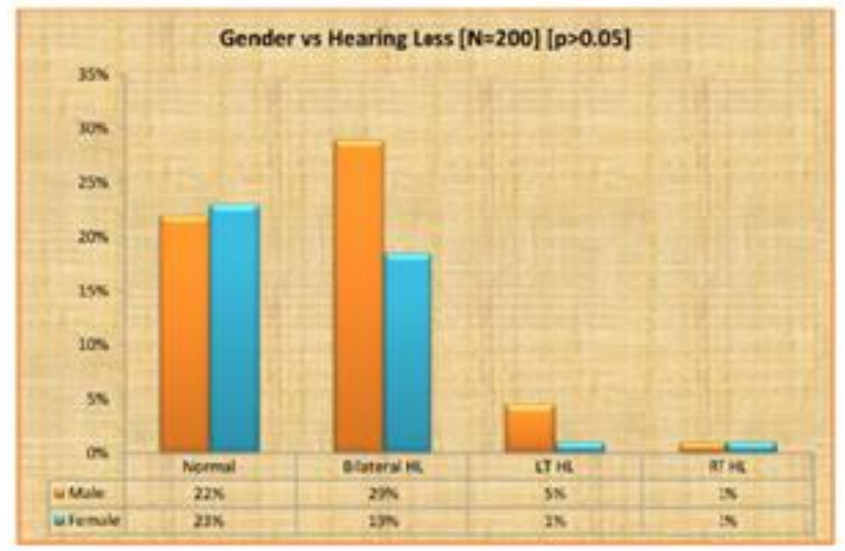

Fig. 5. Gender vs Hearing loss.

TABLE II: DISTRIBUTION OF HEARING LOSS WITH DURATION OF DM

\begin{tabular}{|c|c|c|c|c|c|c|c|}
\hline \multicolumn{8}{|c|}{ Mean DM Duration of Hearing Loss } \\
\hline & \multirow{3}{*}{$\mathrm{N}$} & \multirow{3}{*}{ Mean } & \multirow{3}{*}{ SD } & \multicolumn{2}{|c|}{$95 \%$ CI or Mean } & \multirow{3}{*}{ Minimum } & \multirow{3}{*}{ Maximum } \\
\hline & & & & Lower & Upper & & \\
\hline & & & & Bound & Bound & & \\
\hline Normal & 90 & 3 & 3 & 2 & 4 & 1 & 20 \\
\hline $\begin{array}{c}\text { Bilateral } \\
\text { SNHL }\end{array}$ & 95 & 5 & 3 & 5 & 6 & 1 & 25 \\
\hline LT HL & 11 & 5 & 4 & 3 & 7 & 2 & 15 \\
\hline RT HL & 4 & 5 & 3 & 1 & 9 & 1 & 6 \\
\hline Total & 200 & 4 & 3 & 4 & 5 & 1 & 25 \\
\hline
\end{tabular}




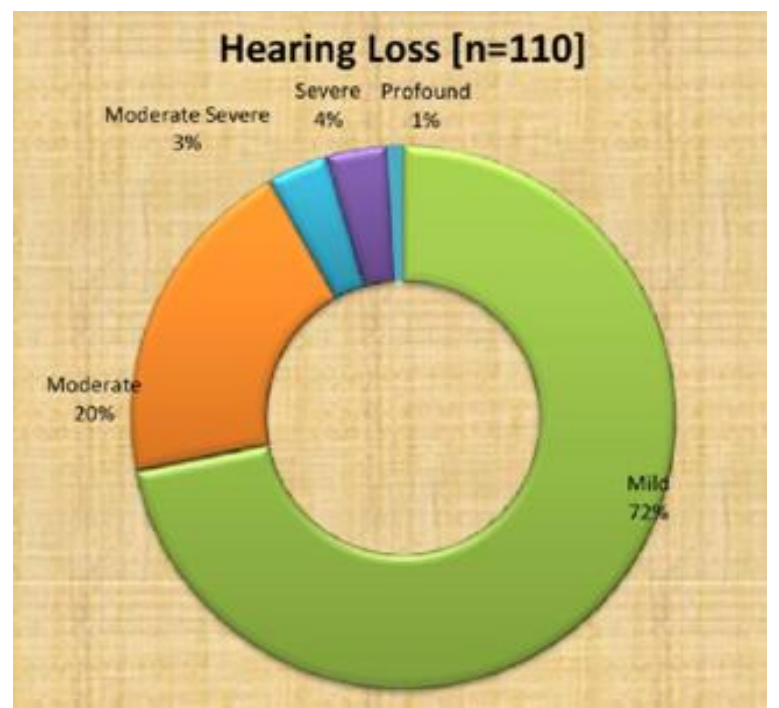

Fig. 6. Degree of Hearing Loss.

\section{DISCUSSION}

Hearing loss is important of hearing and its severity varies from mild to severe or profound and in general hearing loss may be conductive, sensorineural, or mixed. The typical hearing impairment described in diabetic patients is a bilateral sensorineural hearing loss. Diabetes mellitus has been implicated as independent causative factor of sensorineural hearing loss [14].

\section{A. Age}

Our study has evaluated the hearing loss in the patients with diabetes and the influence of hyperglycemia on hearing and it shows $55 \%$ incidence of deafness. And the peak age group being affected with hearing loss in our study was between 50-53 years of age.

In contrast a study conducted by Rajendran S. Anandhalakshmi et a1 [16] showed maximum incidence between 40-50 years of age. On further review, we realize that acquired on set sensorineural hearing loss can occur early in diabetic patients. Usually age-related sensorineural deafness is more common in people more than 60 years of age. But here it is seen that diabetic patients are higher risk of developing this sensory loss at a much younger age group.

It is also that in our study there were more people with diabetes among the age group 51-60 years of age (50\%). The $\mathrm{p}$ value is 0.05 , which makes it statistically significant.

\section{B. Sex}

In our study it was noted that a greater number of diabetic males were affected with hearing loss, than females. In contrast Taylor and Irwin (1978) observed that female patients with diabetes had significantly greater hearing loss when compared with male patients with diabetes.

But according to Cullen and Cinnamond [17], Male patients with diabetes had worse hearing than female patients with diabetes.

From our study, we conclude that sex of an individual is not statistically significant $(p>0.05)$ parameter in considering the males are more prone to develop Diabetes mellitus.

\section{Overall incidence of hearing loss in diabetics}

In our study, we evaluated the hearing loss in the patients and the influence of hyperglycemia on hearing and it shows a 55\% incidence of deafness. Friedman at al [18] showed a $55 \%$ incidence of hearing loss in diabetic patients. Which is the same incidence found in our study.

Kakarlapudi et a1 [19] found that hearing loss was more common in diabetic patients $(13.1 \%)$ than the control nondiabetic healthy subjects.

Wenget a1 [20] noted that among the 67 diabetic subjects examined, $44.8 \%$ of them had profound hearing loss. This is much lesser comparing to our study.

\section{Duration of diabetes}

In our study a greater number of patients with diabetes were found 3-5 years group, about $48 \%$, followed by less than 2 years duration $31 \%$.

Comparing with, the duration of diabetes and hearing loss, more patients in the group 3-5 years had hearing loss, around $49 \%$, followed by less than 2 years, around 32 years. Whereas only $20 \%$ patients were found to have hearing loss in 5-10 years group.

In study it is seen that the duration of diabetes is not a significant criteria for developing sensoineural hearing loss. The $\mathrm{p}$ value is $<0.05$, making it statically significant.

A study by Celik et al [21] observed that as the duration of diabetes increased to 15 years, the incidence of hearing loss also increased. After 15 years of diabetes, the influence on hearing loss was not significant. This change was not observed in our study as cases in our study were all mostly found to be less than 15 years.

\section{E. Overall severity of hearing in individual ear}

It is noted that in the right ear 95 cases had normal hearing, 84 cases had mild hearing loss, 15 had moderate and 3 cases had moderately severe and severe hearing loss respectively.

It is noted that in the left ear, 92 cases had normal hearing, 81 had minimal hearing loss, 16 had moderate loss 8 moderately severe, 2 with severe and 1 with profound hearing loss. Thus, making it statically not significant ( $>0.05$ ). The above data was calculated taking the gender as consideration and compared the hearing. But no significant changes were noted in severity of hearing.

Taking into consideration the duration of diabetes, it is noted that in right ear maximum of $58(30 \%)$ cases had hearing loss among the group 3-5 years, among which 49 $(25 \%)$ cases had mild hearing loss; 6 (3\%) cases had moderate hearing loss and 3 cases (2\%) had moderately severe loss, followed by 5-10 years group where 31 cases (16\%) had hearing loss

And in left ear it is noted that , maximum of 59(30\%) cases had hearing loss among the group 3-5 years, among which $44(22 \%)$ cases had mild hearing loss; $8(4 \%)$ cases had moderate hearing loss and 5 cases $(3 \%)$ had moderately serve loss, followed by 5-10 years group where 32 cases (17\%) had hearing loss.

Thus, we conclude that predominantly mild sensorineural hearing loss in both ears. The $\mathrm{p}$ value is $<0.01$, making it statistically significant. 


\section{F. Overall severity of hearing loss}

In our study, $72 \%$ of individuals with diabetes were noted to have mild sensorineural hearing loss, followed by $20 \%$ with moderate sensorineural hearing loss. Only $1 \%$ had profound hearing loss.

A study conducted by Rajendran at al showed a result similar to our study. The diabetic individuals showed significant high frequency, bilateral, mild to moderate sensorineural hearing loss $(73.3 \%)$ as compared to controls of similar age.

Whereas Weng at al [14] observed that among the 67 diabetic subjects examined, $44.8 \%$ of them had profound hearing loss.

Many studies were conducted to observe the pathogenesis of this sensorineural loss observed in diabetics. During this course, many studies suggested that diabetes is a cause of hearing loss. The probable mechanisms suggested were microangiopathy in the inner ear, neuropathy of cochlear nerve, or even a combination of both. Outer hair cell dysfunction and disruption of endolymphatic potential were noted in some noted in some studies. Some of the tissue effects of diabetes are considered to be related to the polyol pathway, in which glucose is reduced to sorbital.

Generally, the accumulation of Sorbitol is implicated in neuropathy as it causes a decrease in myo inositol content and further leads to decrease in $\mathrm{Na}+\mathrm{K}+\mathrm{ATPase}$ activity [22].

Makishima and Tanaka [23] observed that there was serere atrophy of the spiral ganglion in the basal lamina and the middle turns of cochlea in diabetic individuals with sensorineural hearing loss. It was also observed that 8th nerve reviled changes in the myelin sheath, which showed degeneration and fibrosis of perineurium

Jorgensen [24] in his story noted thickening in the walls of the vasa nervorum in the 8th nerve which lead to the development of acoustic neuropathy.

In the study by Wackym and Linthicum [25] noted small microanogopathic changes in the regions of endolymphatic sac, the stria vascularis and basilar membrance.

Van den Ouweland et al [26] observed mutational changes in the mitochondrial RNA. It was also observed that in a small subset of patients, with maternally inherited diabetes showed some degree of sensorineural hearing loss.

Lisowska et al [27] in their study noted that in diabetic patients, there was abnormality in the function of hair cells in auditory brain stem responses.

Fukushima et al [28] concluded that Type 2 Diabetes lead to changes in cochlea, like significant atrophy of stria vascularies and basal turn, which was the likelihood of hearing loss in their patients.

In our study, we conclude that after analyzing the audiograms of the diabetic patients, it is noted that they are more prone to develop mild to moderate sensorineural hearing loss. The duration of diabetes as well as sex of the individual were found to have no effect on the incidence of hearing loss.

\section{REFERENCES}

[1] Dhingra P.L. Diseases of Ear, Nose and Throat, Elsevier edition, 2009.

[2] Colin Mathersl. Andrew Smith2, Marisol Concha3; Global burden of hearing loss in the year 2000 .

[3] World Health Organization. World Health Report 2001. Mental health; New Understanding, New Hope, Geneva, World Health Organization 2001.

[4] WHO Study Group. Diabetes mellitus. Technical Report Series 727. Geneva; World Health Organiztion, 1985.

[5] Savage PJ. Bennion LJ. Bennett PH. Normalization of insulin and glucagon secreation in ktosis-resistant diabetes mellitus with prolonged diet therapy. J Clin Endocrinol Metab 1979;49;830 (1)833.

[6] Agner T. Damm p.Binder C. Remission in IDDM; prospective study of basal C-peptide and insulin dose in 268 consecutive patients. Diabetes Care 1987

[7] Gauin JR III, Alberti KGMM, Davidson MB, et al. Report of the Expert Committee on the Diagnosis Mellitus Diabetes care 1997;20.1183-1197.

[8] Tanks S. Kobayashi T. Momostu T. A novel subtype 1 diabetes mellitus. NEng J Med 2000;342;1835-1837.

[9] 9) Tuner Re. Cull CA, Frighi V, et al. Glycemic control with diet, suphonyl urea. Metformin, or insulin in patients with type $2 \mathrm{DM}$; Progressive requirement for multiple therapies. UK Prospective diabetes study group. JAMA 1999;281;2005-2012.

[10] King H. Rewers M. Global estimates for prevalence of diabetes mellitus and impaired glucose tolerance in adults. Diabetes care $1993 ; 16 ; 617-621$.

[11] Boyyko EJ, de courten M, Zimmet PZ, et al, Features of the metabolic syndrome predit higher risk of the diabetes and impresseded glucose tolerance; a prospective study in Maurtitus, Diabet Med 2003;20;915920 .

[12] Gareth Williams John C.Pickup. Text book of diabetes mellitus. Blackwell publishing Ltd, Oxford, Third edition, 2003.

[13] Fukushima H, Cureoglu S.Schachern PA, Paparella MM, Harada T Oktay MF, Effects of type 2 diabetes mellitus on cochlear structure in humans, Arch Otolaryngol Head Neck Surg.2006;132(9);934-8.

[14] Maia CA, Campos Ca Diabetes mellitus as etiological factor of hearing loss. Rev Bras Otorrinolaringol. 2005;71;208-214.

[15] Taylor,I,G,Irwin,J. Some audiological aspects of diabetes mellitus, J.Laryngol Otol.1978;92;99-113.

[16] Rajendran s, Anandhalakshmi, Mythili B, ViswanTHA Rao Evaluation of the Incidence of Sensorineural hearing loss in Patients with Type 2 Diabetes Millitus, Int J Biol Med Res.2011;2(4); 982 987.

[17] Cullen JR. Cinnamond MJ. Hearing loss in diabetes. Int J Laryngol Otol.1993;107(3);179-82.

[18] Friedman SA, Schulman RH, Weiss S. Hearing and diabetic neuropathy, Arch Intern Med. 1975;135(4);573-6.

[19] KAkarlapudii V. Sawyer R, Staeeker H. The effect of diabetes on sensorineural hearing loss Otol Neurotol. 200;24(3); 382-6.

[20] Weng SF, Chan YS , Hus CJ, Tseng FY, Clinical features of sudden sensorineural heraring loss in diabetic patients Laryngoscope 2005;115(9); 1676-80.

[21] Celik O, Yalcin S, Celebi H, Ozturk A, Hearing loss in insulin dependent diabetes mellitus. Auris Nasus Larynx 1996;23;127-32.

[22] Dennis Kasper, Anthony S, Fauci, Dan L.Longo, Eugene Braunwald, Stephen L. Hauser, J. Larry Jameson and Joseph Losecalzo, Harrison's Principles of Internal Medicine, MeGraw-Hill Companies Inc. United States of America 17 th Ed.2008.

[23] Makashima, K., Tanaka, K. Pathological changes of the inner ear and central auditorypathways in diabetics. Ann Otol Rhinol Laryngol.1971;80;218-288.

[24] Jorgensen,M.B>.The inner ear in diabetes mellitus. Arch Otolaryngol Head Neck Surg;1961;74;31-39.

[25] Wackym. P.A. Linthicum F.H. (1986) Diabetes mellitus and hearing loss, Clinical and histopathologic relationship. Am. J. Otolaryngol. 1986; 7; 176-1823.

[26] Van den Ouweland JM, Lemakes HH Gerbitz KD, maassen JA, Maternally inherited diabetes and deafness (MIDD); A distinet subtype of diabetes associated with a mitochondrial t RNALeu (urr) gene point mutation. Muscle Nerve. 1995;3;s124-30.

[27] Lisowska G.Namyslowski G. Morawski K, Strojek K. Otoacoustic emissions and auditory brain stem responses in insulin dep[endent diabetic patients. Otolaryngol Pol.2002;56(2);217-25.

[28] Fukushima H.Cureoglu S.Schachern PA, Paparella MM, Harada T,Oktay MF. Effects of type 2 diabetes mellitus on cocochlear structure in humans, Arch Otolaryngol Had Neck Surg. 2006; 132(9). 
[29] Fangchao Ma, Orlando Gomez - Marin., David J.Lee, Thomas Balkany. Diabetes and hearing impairment in Mexican American adults; a population - head study, J.Laryngol Otol. 1998;112'835839.

[30] Gibbin KP, Davis CG, A hearing survey in diabetes mellitus ClinOtaryngol Allied Sei. 1981;6(5);345-50.

[31] Austin DF, Konrad- Martin D, Griest S, Memillan GP, MeDermott D, Fausti S. Diabetes related changes in hearing. Laryngoscope.2009;119(9);1788-96.

[32] Sakuta H, Suzuki T. Yasuda H, Ito T.Type 2 Diabetes and hearing losss in personnel of the Self-Defense Forces. Diabetes Res Clin Pract, 2007;75(2); 229-34. 